\title{
Stable Isotope-Resolved Metabolomic Differences between Hormone-Responsive and Triple-Negative Breast Cancer Cell Lines
}

\author{
Jason H. Winnike, ${ }^{1}$ Delisha A. Stewart, ${ }^{2}$ Wimal W. Pathmasiri, ${ }^{2}$ \\ Susan L. McRitchie, ${ }^{2}$ and Susan J. Sumner $\mathbb{D D}^{2}$ \\ ${ }^{1}$ Analytical Sciences, David H. Murdock Research Institute, Kannapolis, NC 28081, USA \\ ${ }^{2}$ NIH Eastern Regional Comprehensive Metabolomics Resource Core, Department of Nutrition, \\ University of North Carolina at Chapel Hill Nutrition Research Institute, Kannapolis, NC 28081, USA
}

Correspondence should be addressed to Susan J.SSumner; susan_sumner@unc.edu

Received 14 December 2017; Accepted 13 September 2018; Published 30 September 2018

Academic Editor: Debra A. Tonetti

Copyright (C) 2018 Jason H. Winnike et al. This is an open access article distributed under the Creative Commons Attribution License, which permits unrestricted use, distribution, and reproduction in any medium, provided the original work is properly cited.

\begin{abstract}
Purpose. To conduct an exploratory study to identify mechanisms that differentiate Luminal A (BT474 and MCF-7) and triplenegative (MDA-MB-231 and MDA-MB-468) breast cancer (BCa) cell lines to potentially provide novel therapeutic targets based on differences in energy utilization. Methods. Cells were cultured in media containing either $\left[\mathrm{U}_{-}{ }^{13} \mathrm{C}\right]$-glucose or $\left[\mathrm{U}_{-}{ }^{13} \mathrm{C}\right]$-glutamine for 48 hours. Conditioned media and cellular extracts were analyzed by ${ }^{1} \mathrm{H}$ and ${ }^{13} \mathrm{C}$ NMR spectroscopy. Results. MCF-7 cells consumed the most glucose, producing the most lactate, demonstrating the greatest Warburg effect-associated energy utilization. BT474 cells had the highest tricarboxylic acid cycle (TCA) activity. The majority of energy utilization patterns in MCF-7 cells were more similar to MDA-MB-468 cells, while the patterns for BT474 cells were more similar to MDA-MB-231 cells. Compared to the Luminal A cell lines, TNBC cell lines consumed more glutamine and less glucose. BT474 and MDA-MB- 468 cells produced high amounts of ${ }^{13} \mathrm{C}-$ glycine from media $\left[\mathrm{U}_{-}{ }^{13} \mathrm{C}\right]$-glucose which was integrated into glutathione, indicating de novo synthesis. Conclusions. Stable isotopic resolved metabolomics using ${ }^{13} \mathrm{C}$ substrates provided mechanistic information about energy utilization that was difficult to interpret using ${ }^{1} \mathrm{H}$ data alone. Overall, cell lines that have different hormone receptor status have different energy utilization requirements, even if they are classified by the same clinical BCa subtype; and these differences offer clues about optimizing treatment strategies.
\end{abstract}

\section{Introduction}

Triple-negative breast cancer (TNBC) is considered to be one of the most aggressive subtypes of $\mathrm{BCa}$ based on its clinical characteristics, including increased proliferative rate, high metastatic potential, and shorter survival outcomes (overall and relapse-free) [1-5]. It accounts for 15-20\% of all diagnosed BCa cases [6-8] and has an increased prevalence in African American and Asian women ( 30\%-65\%) compared to other ethnicities [9-16]. TNBC is defined by the lack in expression of the common $\mathrm{BCa}$ markers, estrogen receptor (ER), progesterone receptor (PR), and epidermal growth factor receptor 2/HER2/neu (HER2) [17], which classify other types of $\mathrm{BCa}$ and serve as targets for specific treatments; thus, development of targeted therapies for TNBC has been severely hampered. Innovative approaches that identify relevant targets could lead to new therapies that could augment the efficacy of current standard-of-care surgical, chemotherapeutic, or radiation-dependent interventions [18-20].

Now an established hallmark of cancer, aberrant energy metabolism has provided a wealth of information on how tumor cells initiate, progress, and spread [21,22]. For example, measurement of glycolytic activity is used to identify key metabolic perturbations that significantly impact tumor cell growth and viability, by comparing alterations in glucose uptake and lactate production, as well as other rate-limiting enzymes involved in the endogenous pathways. Another important essential amino acid that has shifted some attention from glucose as a primary energy source in the past few years is glutamine [23] and the process of glutaminolysis [24], 
which can provide significant energy needs (i.e., NADPH) of rapidly proliferating cells [25]. Metabolomics methods employing stable isotope labeled compounds, such as ${ }^{13} \mathrm{C}$ glucose or ${ }^{13} \mathrm{C}$-glutamine, can be used to interrogate the energetic flux that cancer cells depend on to thrive and avoid host programs for destruction.

In a previous study [26], we compared the metabolic and inflammatory responses of these hormone receptor-positive (Luminal A) and TNBC cell lines following treatment with the widely used chemotherapeutic paclitaxel $\left(\operatorname{Taxo}^{\circledR}{ }^{\circledR}\right.$ ). There, we showed differences between both the cells classified by the same subtype (BT474 versus MCF-7 and MDA-MB-231 versus $\mathrm{MDA}-\mathrm{MB}-468)$ and between the two subtype cell models (Luminal A versus TNBC) [26]. Based on our findings, we felt further investigation of the metabolic differences was warranted. This current study presents results to help better understand metabolic differences of these two cell models of different hormone receptor status BCa subtypes. This may identify new TNBC targets, reveal potential points for modulation, and ultimately improve the ability to design therapeutics that disrupt their primary energy utilization paradigms [27].

\section{Materials and Methods}

2.1. Cell Culture and Treatment. Luminal A BCa cell lines (BT474 and MCF-7) and TNBC cell lines (MDA-MB-231 and MDA-MB-468) were purchased from ATCC and cultured in DMEM media (Gibco/Life Technologies) supplemented with $10 \%$ FBS and $1 \%$ antibiotic/antimycotic. All ATCC cell lines undergo authentication tests (i.e., for mycoplasma negativity) during the accessioning process, which is described in the online ATCC brochure Maintaining High Standards in Cell Culture (http://www.atcc.org/). Cells were maintained in culture, incubated under humidified conditions at $37^{\circ} \mathrm{C}$ in $5 \%$ $\mathrm{CO}_{2}$.

$\left[\mathrm{U}_{-}{ }^{13} \mathrm{C}\right]-$ Glucose was purchased from Cambridge Isotope Laboratories (Tewksbury, MA, USA) and [ $\left.\mathrm{U}_{-}{ }^{13} \mathrm{C}\right]$-glutamine was purchased from Sigma-Aldrich (St. Louis, MO, USA). Each cell line was plated on $10 \mathrm{~cm}$ dishes with DMEM growth media containing $4.5 \mathrm{~g} / \mathrm{L}$ glucose $+2 \mathrm{mM}$ glutamine (Gibco) for $24 \mathrm{hr}$. Media was removed and cells were washed three times with sterile 1X PBS and treated for $48 \mathrm{hr}$ in regular high glucose DMEM, DMEM (-glucose) supplemented with [U${ }^{13} \mathrm{C}$ ]-glucose or DMEM (-glutamine) supplemented with [U$\left.{ }^{13} \mathrm{C}\right]$-glutamine. Following incubation, $1 \mathrm{~mL}$ media aliquots were collected and stored at $-80^{\circ} \mathrm{C}$. Cells remaining on dishes were washed three times with ice-cold 1X PBS and extracted using a modified Folch method [28, 29]. Briefly, cells were quenched with 50:50 ice-cold acetonitrile:water, scraped off dishes, and collected into $15 \mathrm{~mL}$ tubes containing zirconia beads. Cold chloroform was added and each tube was vigorously vortexed on a multitube vortexer for three $30 \mathrm{sec}$ pulses. Tubes were centrifuged at $3,700 \mathrm{rpm}$ for $60 \mathrm{~min}$ at $4^{\circ} \mathrm{C}$, and the aqueous fractions were transferred to cryotubes, while the organic fractions were collected into glass vials. The remaining protein layer and residual aqueous and lipid layers were transferred to Lo-Bind microcentrifuge tubes, cold chloroform:methanol (2:1) was added, and the tubes were quickly vortexed and then centrifuged at 15,000 rpm for $20 \mathrm{~min}$ at $4^{\circ} \mathrm{C}$. The remaining aqueous and lipid fractions were transferred into collection tubes indicated above, and the protein pellets were dried for $20 \mathrm{~min}$ on a Speedvac (no heat) and weighed. All samples were stored at $-80^{\circ} \mathrm{C}$ except for the aqueous fractions which were immediately lyophilized to dryness and then stored at $-80^{\circ} \mathrm{C}$ until preparation for NMR analysis. Each condition was performed in triplicate.

2.2. NMR Sample Preparation and Data Acquisition. Media samples were removed from $-80^{\circ} \mathrm{C}$ and thawed at $4^{\circ} \mathrm{C}$. Samples were vortexed briefly and centrifuged at 18,000 rcf and $4^{\circ} \mathrm{C}$ for $15 \mathrm{~min}$ and a $200 \mu \mathrm{L}$ aliquot was removed to a microcentrifuge tube. Next, $1 \mathrm{~mL}$ of ice-cold methanol:chloroform extraction solvent (3:1) was added and samples were vortexed for $30 \mathrm{sec}$ and centrifuged at the same conditions listed above. Supernatants were transferred to new microcentrifuge tubes and dried overnight under a gentle flow of $\mathrm{N}_{2}$. Samples were reconstituted in $700 \mu \mathrm{L}$ of a deuterium oxide $\left(\mathrm{D}_{2} \mathrm{O}\right.$, Aldrich, St. Louis, MO, USA) solution containing $0.6 \mathrm{mM}$ 4,4-dimethyl-4-silapentane-1-sulfonic acid (DSS-D6, Chemical Shift Indicator), $0.6 \mathrm{mM}$ Imidazole ( $\mathrm{pH}$ indicator), and $0.2 \% \mathrm{NaN}_{3}$ and vortexed and centrifuged at the same conditions listed above. Following centrifugation, $600 \mu \mathrm{L}$ aliquots were transferred to $5 \mathrm{~mm}$ NMR tubes for data acquisition. NMR spectra were acquired on a Bruker Avance III $600 \mathrm{MHz}$ NMR spectrometer (Bruker-Biospin, Rheinstetten, Germany) using a cryogenically cooled $5 \mathrm{~mm}$ ATMA probe at $25^{\circ} \mathrm{C}$. For ${ }^{1} \mathrm{H}$ spectra, a 1D NOESY pulse sequence (noesyprld) with water presaturation during the $2 \mathrm{sec}$ relaxation delay and $100 \mathrm{~ms}$ mixing time was used, and 128 transients were collected into $16 \mathrm{k}$ data points with a spectral width of $6602.1 \mathrm{~Hz}(11 \mathrm{ppm})$ and an acquisition time of $2.48 \mathrm{sec}$.

Lyophilized cellular extracts were reconstituted in the same NMR solution as used for the conditioned media. The samples were vortexed and centrifuged at 12,000 rcf for $3 \mathrm{~min}$; then a $600 \mu \mathrm{L}$ aliquot of each sample supernatant was transferred into $5 \mathrm{~mm}$ NMR tubes (Bruker-BioSpin, Switzerland) for data acquisition. For ${ }^{1} \mathrm{H}$ spectra, the same 1D NOESY pulse sequence as described in the previous paragraph was used, except the number of transients was increased from 128 to 256 . For ${ }^{13} \mathrm{C}$ spectra, a $1 \mathrm{D}{ }^{13} \mathrm{C}$ pulse sequence (zgpg30) was used with a 2 s relaxation delay and 512 transients were collected into $32 \mathrm{k}$ points, with a spectral width of $36057.7 \mathrm{~Hz}(239 \mathrm{ppm})$ and an acquisition time of $0.9088 \mathrm{sec}$. Additionally, two-dimensional NMR spectra were acquired on a few select samples to aid in peak identification. These 2D-HSQC spectra were acquired at $25^{\circ} \mathrm{C}$ using 16 transients, 256 points in the ${ }^{13} \mathrm{C}$ dimension, and 512 points in the ${ }^{1} \mathrm{H}$ dimension. The relaxation delay was $1.5 \mathrm{~s}$, spectral widths were $8012.8 \mathrm{~Hz}(13.4 \mathrm{ppm})$ and $24997.3 \mathrm{~Hz}$ (165.6 ppm) for ${ }^{1} \mathrm{H}$ and ${ }^{13} \mathrm{C}$, respectively, and the acquisition time was $0.0639 \mathrm{~s}$.

2.3. NMR Data Analysis. All spectra were imported into MestReNova 10.0.1 (Mestrelab Sesearch SL, Santiago de Compostela, Spain) for processing. ${ }^{1} \mathrm{H}$ spectra were zerofilled to $64 \mathrm{k}$ points, apodized $(0.5 \mathrm{~Hz}$ for media and $1 \mathrm{~Hz}$ 
TABLE 1: Semiquantitative concentrations of intracellular metabolites*.

\begin{tabular}{|c|c|c|c|c|c|c|c|c|}
\hline \multirow[b]{2}{*}{ Metabolites } & \multicolumn{2}{|c|}{ BT474 } & \multicolumn{2}{|c|}{ MCF-7 } & \multicolumn{2}{|c|}{ MDA-MD-231 } & \multicolumn{2}{|c|}{ MDA-MB-468 } \\
\hline & ${ }^{13} \mathrm{C} \mathrm{Glc}$ & ${ }^{13} \mathrm{C} \mathrm{Gln}$ & ${ }^{13} \mathrm{C}$ Glc & ${ }^{13} \mathrm{CGln}$ & ${ }^{13} \mathrm{C} \mathrm{Glc}$ & ${ }^{13} \mathrm{C} \mathrm{Gln}$ & ${ }^{13} \mathrm{C} \mathrm{Glc}$ & ${ }^{13} \mathrm{CGln}$ \\
\hline Adenosine & $229.2(210.1)$ & $50.1(60.4)$ & $28.1(35)$ & $0(0)$ & $28.6(32)$ & $2.8(4.8)$ & $296.2(39.7)$ & $44.9(17.2)$ \\
\hline Alanine & $7293.5(2003)$ & $56.5(97.9)$ & $981.1(191.1)$ & $13.3(23.1)$ & $4225.2(389.6)$ & $155(158.4)$ & $3947.3(468.7)$ & $25.9(26.8)$ \\
\hline Aspartate & $762.1(236.5)$ & $526.4(63.8)$ & $60.4(104.6)$ & $47.7(50.9)$ & $679.5(133)$ & $545.7(101.3)$ & $30.8(31.5)$ & $44.7(39.9)$ \\
\hline AXP & $278.4(171.9)$ & $0(0)$ & $74.5(50.7)$ & $23.3(10.6)$ & $95.6(22.4)$ & $35.5(27.9)$ & $265.4(62.9)$ & $54.2(36.8)$ \\
\hline Glucose & $6791.1(2295.2)$ & $422.3(327)$ & $2103.3(128.9)$ & $914.6(440.3)$ & $2346(168.3)$ & $607.9(96.1)$ & $2989.7(743.3)$ & $353(83.1)$ \\
\hline Glutamate & $1765.2(531.5)$ & $1103.6(242.6)$ & $956(227.8)$ & $894.6(88.5)$ & $972.3(163.2)$ & $528.8(120.7)$ & $945.3(205.8)$ & $398.9(145.5)$ \\
\hline Glutamine & $534.9(497.9)$ & $7697.9(1913.5)$ & $483.4(285.1)$ & $3030(128.1)$ & $2879.8(512)$ & $4812.5(1445.6)$ & $2318(474.2)$ & $2081.8(667.6)$ \\
\hline Glycine & $1098.1(374.1)$ & $72(124.7)$ & $0(0)$ & $7.8(13.6)$ & $0(0)$ & $0(0)$ & $1145.3(169.4)$ & $14.5(25.2)$ \\
\hline Lactate & $2167.3(653.3)$ & 75.4 (15.1) & $1623.7(515.1)$ & $149.3(26.9)$ & $472.8(63.5)$ & $59.8(32.7)$ & $1518.7(320.8)$ & $84.3(51)$ \\
\hline Glutathione & $148.3(72.4)$ & $23.8(41.3)$ & $7.8(13.5)$ & $1.9(3.4)$ & $0(0)$ & $0(0)$ & $165.9(67.7)$ & $6.3(11)$ \\
\hline Proline & $170.2(131.3)$ & $108.5(86.9)$ & $689.4(183.5)$ & 491 (198) & 390.5 (128.8) & $160.9(45.4)$ & $472.5(68.1)$ & $161.6(14.7)$ \\
\hline UDP-GlcNAc & $1212.9(387.9)$ & 146 (127.7) & $100.1(86.8)$ & $63.5(12.5)$ & 705.9 (126.7) & $24.2(4.6)$ & $357.4(107.1)$ & $26.4(4)$ \\
\hline UDP-Glucose & $1422.4(267.1)$ & $21.9(38)$ & $357.2(79.9)$ & $21(18.4)$ & $719.4(80.6)$ & $43.2(68.4)$ & $690.6(93)$ & $82.1(16.5)$ \\
\hline Uridine & $15.9(27.5)$ & $18.4(31.9)$ & $302.8(46)$ & $5.8(10)$ & $82.9(71.4)$ & $33.1(27.8)$ & $234.5(37.9)$ & $32(46.2)$ \\
\hline Uridine/UDP- & $2275.9(409.5)$ & $86.5(149.8)$ & 721.7 (122.3) & $0(0)$ & $1331.4(127.8)$ & 9.7 (16.9) & $1247.3(310.5)$ & $32.8(38.6)$ \\
\hline
\end{tabular}

* Semiquantitative values have been normalized to pellet weight and are unitless. Values represent average among three replicates and the standard deviation is in parentheses.

for extract), and Fourier transformed. Spectra were manually phased and baseline corrected with a linear first-degree polynomial and referenced to DSS. The peaks in the spectra were then globally deconvoluted using the Global Spectral Deconvolution (GSD) peak picking routine (2 fitting cycles, optimized for average peaks). Peak lists containing chemical shifts and peak area were exported to Microsoft Excel (Microsoft Corporation, Redmond, WA) for further analysis. Peak areas corresponding to metabolites were identified, and using the peak area of the known concentration of DSS, the relative concentration of metabolites was calculated. Protein pellet masses were used for normalization of metabolite concentration data. Carbon spectra were zero-filled to $64 \mathrm{k}$ points, apodized with a $10 \mathrm{~Hz}$ exponential curve, and Fourier transformed. Spectra were manually phased and baseline corrected with a 13-degree polynomial and referenced to DSS. The peaks in the spectra were then manually integrated and peak lists were exported to Microsoft Excel for further analysis. Peak areas corresponding to identified metabolites were measured for determining relative concentrations and protein pellet masses were used to normalize the metabolite semiquantifications. Media production and consumption values were calculated using the ${ }^{12} \mathrm{C}$ media experimental replicates, with the difference from fresh unused media being normalized to pellet weight. As mentioned above, each condition was measured in triplicate and therefore all measurements of intracellular concentrations and media production and consumption are presented as averages with standard deviations indicated by parentheses in the first two tables. Fold changes were calculated in the third table for all pairwise comparisons between cell lines, relative to each cell line. Hypothesis testing was not conducted due to the small sample size in this pilot study. All raw metabolomics data is publicly available at the NIH Common Fund Metabolomics Data
Repository and Coordinating Center website, Metabolomics Workbench: http://www.metabolomicsworkbench.org/data.

\section{Results and Discussion}

3.1. Glycolysis, Glutaminolysis, and the Citric Acid Cycle. Table 1 shows some of the differences of glucose and glutamine utilization by each cell line, based on integration of both ${ }^{1} \mathrm{H}$ and ${ }^{13} \mathrm{C}$ carbon NMR signals from the cellular extracts and cultured media. Across the four cell lines, glycolytic-dependent differences were immediately evident upon review of the spectral data (Supplemental Figure 1A) and likewise for glutamine peaks in the ${ }^{13} \mathrm{C}$-glutamine spectra (Supplemental Figure 1B). Luminal A MCF-7 cells used the most glucose and, not surprisingly, produced the most lactate, indicating the Warburg effect [30] being a very active energy utilization mechanism (Figures $1(\mathrm{a})-1(\mathrm{~d})$ ). Additionally, very little ${ }^{13} \mathrm{C}$-aspartate is produced from [U$\left.{ }^{13} \mathrm{C}\right]$-glucose or $\left[\mathrm{U}_{-}{ }^{13} \mathrm{C}\right]$-glutamine, suggesting little TCA activity in the cultured cells. Similarly, this small production of aspartate was also seen in triple-negative MDA-MB-468 cells (Figures $1(\mathrm{~g})$ and $1(\mathrm{~h})$ ).

On the other hand, the BT474 Luminal A cell line had high alanine and low lactate production, seen in both the intracellular and media samples (Figures $1(\mathrm{c})$ and $1(\mathrm{~d})$ ), in addition to high ${ }^{13} \mathrm{C}$-aspartate production from $\left[\mathrm{U}^{13} \mathrm{C}\right]$ glucose or $\left[\mathrm{U}_{-}{ }^{13} \mathrm{C}\right]$-glutamine, indicative of high TCA activity. Their lower glucose and glutamine utilization may be indicative of this more efficient use of these energy substrates. A similarly high level of ${ }^{13} \mathrm{C}$-aspartate production from [U$\left.{ }^{13} \mathrm{C}\right]$-glucose and $\left[\mathrm{U}_{-}{ }^{13} \mathrm{C}\right]$-glutamine was also seen in the MDA-MB-231 (TNBC) cell line (Figures $1(\mathrm{~g})$ and $1(\mathrm{~h})$ ), and as expected we saw a smaller production of lactate in the media, 


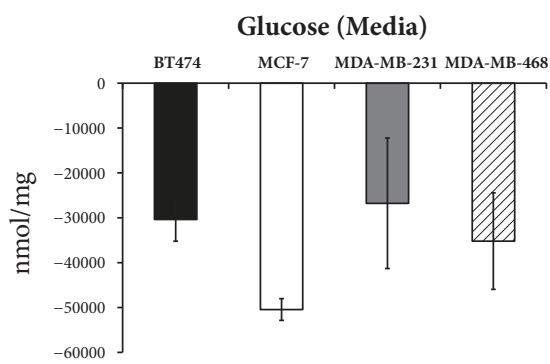

(a)

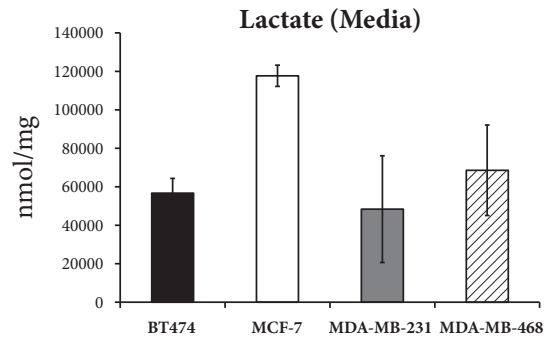

(d)

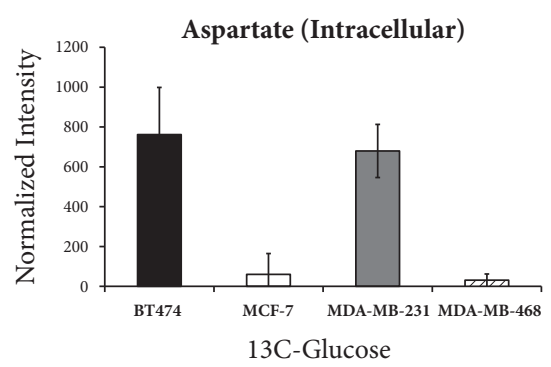

(g)

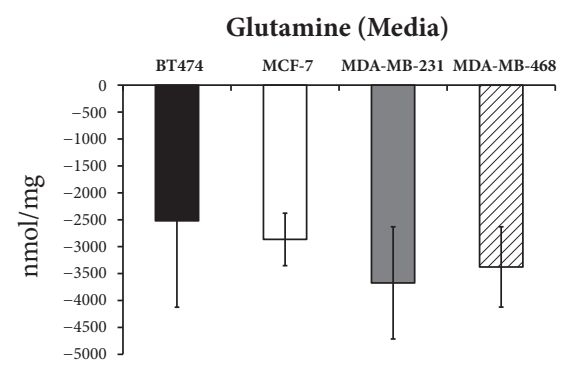

(b)

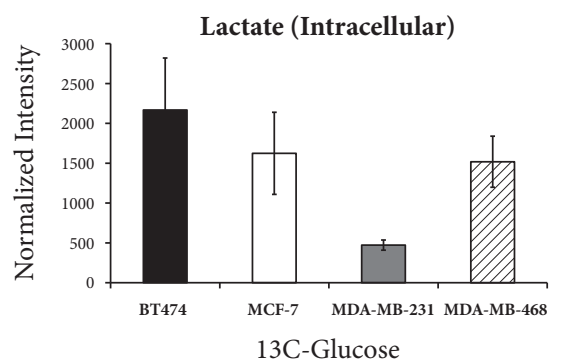

(e)

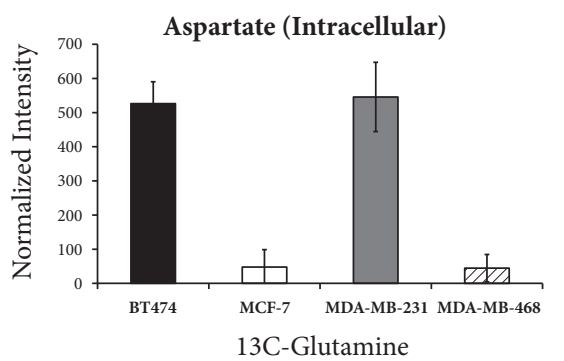

(h)

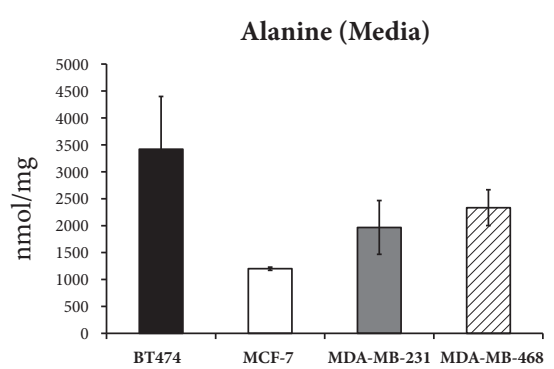

(c)

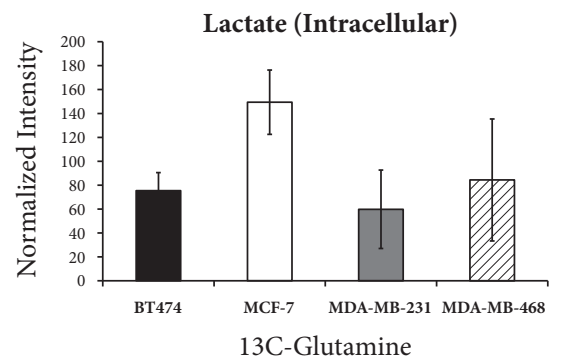

(f)

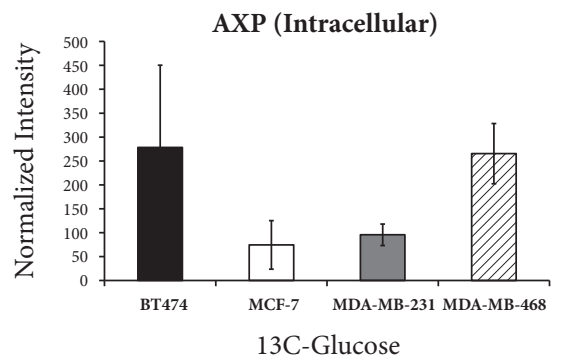

(i)

FIGURE 1: Intracellular and media levels for selected metabolites of interest. Glucose and glutamine values indicate media consumption. AXP is the sum of AMP, ADP, and ATP which have overlapping peaks that are difficult to differentiate in this case. Graphs are presented as averages of three replicate measurements for each condition/cell line with the error bars reflecting standard deviation between replicates.

compared to the other TNBC cells (Figures 1(d) and 1(e)). There was also a higher catabolism of the media glutamine in the MDA-MB-231 cells (Table 2). Thus, the high ${ }^{13} \mathrm{C}$ aspartate, low media lactate, lower glucose catabolism, and higher glutamine catabolism seem to indicate increased TCA activity and lower anaerobic glycolysis in these cell lines that represent different subtypes of the disease, and our data provide a different way to classify them. Interestingly, in our previously published study, we described the responses of these four cell lines to treatment with the chemotherapeutic drug paclitaxel, showing by unsupervised multivariate analysis [26] that, in the absence of drug, MCF-7 and MDA-MB-468 cells cluster together and likewise BT474 and MDA-MB-231. This observation seems puzzling because it is assumed that the cell lines are most similar based on hormone receptor status and therefore by clinical/molecular subtype classification. In fact, in two previous studies, comparing BCa cell lines across different subtypes, we have shown the lines cluster together by subtype based on both genomic profiles [31] and expression pattern changes after stromal macrophage interaction [5]. Thus, because both BT474 $\left(\mathrm{HER}^{+}\right)$and MCF-7 (HER2 ${ }^{-}$) cells express ER and PR and are accepted as representative of the Luminal A subtype, it was not expected that BT474 would be more metabolically similar to the MDA-MB-231, triple-negative line and likewise the MCF-7 luminal cells more metabolically similar to the triplenegative MDA-MB-468 cells. Our data suggests that, in addition to a potentially new way to classify BCa cell lines, HER2 status may contribute a more significant metabolic role toward energy-dependent mechanisms. These findings may be particularly relevant when considering response to different types of treatments, especially when developing novel targeted strategies.

3.2. Nucleotide Metabolism. The following nucleotides could be seen by either ${ }^{13} \mathrm{C}$ or ${ }^{1} \mathrm{H}$ NMR spectroscopy: adenosine mono-, di-, or triphosphate (AXP) (Figure 1(i)), uridine, UDP-glucose, and UDP-N-acetylglucosamine (UDPGlcNAc). Both UDP-glucose and UDP-N-acetylglucosamine production (measured via ${ }^{13} \mathrm{C}$ enrichment in ribose and 
TABLE 2: Metabolite consumption and production in conditioned medias.

\begin{tabular}{lcccc}
\hline Metabolite & BT474 & MCF-7 & MDA-MB-231 & MDA-MB-468 \\
\hline Glucose & $30381.9(4849.4)$ & $50449.5(2418.9)$ & $26775.3(14543.3)$ & $35193.2(10767.5)$ \\
Glutamine & $2520.4(1605.3)$ & $2865.5(487.3)$ & $3673.5(1042.1)$ & $3376.1(746)$ \\
Isoleucine & $1088.1(194.2)$ & $504.3(156.5)$ & $1091.9(94.3)$ & $843.4(142.3)$ \\
Leucine & $1897.8(392.2)$ & $1341.3(197.9)$ & $1538.6(244.2)$ & $1488.2(126.3)$ \\
Methionine & $330.5(102.2)$ & $174.2(160.1)$ & $253.9(81.2)$ & $252.2(38.8)$ \\
Phenylalanine & $55.0(52.9)$ & $47.5(47.2)$ & $156.5(159.2)$ & $184.5(80.1)$ \\
Threonine & $133.1(133.3)$ & $187.5(163.7)$ & $368.6(324.3)$ & $447.5(140.6)$ \\
Tryptophan & $31.9(35.3)$ & $33.1(29.3)$ & $50.1(22.9)$ & $41.4(16.6)$ \\
Tyrosine & $158.6(95.6)$ & $186.8(52.2)$ & $208.2(122.5)$ & $215.4(87.4)$ \\
Valine & $1141.9(250.6)$ & $671.5(162.1)$ & $1056.7(124.9)$ & $858.3(16)$ \\
\hline 2-Hydroxy-butyrate & $388.4(173.5)$ & $223.3(51.2)$ & $513.1(150.9)$ & $368.8(172.5)$ \\
Acetate & $144.4(67.4)$ & $95.2(30)$ & $1966.6(49.5)$ & $115.6(124.6)$ \\
Alanine & $3420.3(978.3)$ & $1200.9(29.8)$ & $287.1(124.8)$ & $2333.5(332.8)$ \\
Glutamate & $1010.2(390.5)$ & $1385.2(306.5)$ & $48395.6(27755.1)$ & $68584.2(23542.9)$ \\
Lactate & $56700(7688)$ & $117705.8(5518)$ & $(302.8)$ \\
\hline
\end{tabular}

Averages (in $\mathrm{nmol} / \mathrm{mg}$ ) calculated from ${ }^{12} \mathrm{C}$ signals. Standard deviations in parentheses normalized to dried pellet weight. Consumption is reflected by bolded metabolites. Production is reflected by italicized metabolites.

glucosamine moieties, respectively) are mirrored by opposite ${ }^{13} \mathrm{C}$ enrichment trends in uridine (measured via ${ }^{13} \mathrm{C}$ enrichment in the ribose moiety). Thus, it appears that the uridine pool very closely reflects the production of nucleotide sugars in the sense that, as its pool decreases, it is utilized for nucleotide sugar production. Table 3 indicates the fold-change differences between intracellular, produced, and consumed metabolite concentrations from Tables 1 and 2, while Figure 2 shows an overall picture of these key pathways and relative metabolite changes.

The low concentration of ${ }^{13} \mathrm{C}$ labeled uridine and high concentrations of labeled AXP as well as the nucleotide sugars from the $\left[\mathrm{U}^{-13} \mathrm{C}\right]$-glucose in the media of BT474 cells may be a consequence of the seemingly higher aerobic TCA activity seen in these cells compared to the other three lines. Additionally, a much higher intracellular concentration of creatine was seen in BT474, which catalyzes the formation of ATP from ADP. Since anaerobic glycolysis is the less efficient way of generating energy from glucose, the other cell lines may be prioritizing glucose for anaerobic catabolism. This appears to be the case for the MCF-7 cells. Regarding uridine, the nucleotide sugars, and AXP, MCF-7 cells had a completely opposite trend compared to the BT474 cells. Additionally, glucose consumption, total lactate production, and ${ }^{13} \mathrm{C}$ aspartate concentrations (from both $\left[\mathrm{U}_{-}{ }^{13} \mathrm{C}\right]$-glucose and $\left[\mathrm{U}_{-}{ }^{13} \mathrm{C}\right]$-glutamine) have opposite trends for these two Luminal A lines, demonstrating the MCF-7 cells exhibit higher anaerobic glycolysis and lower TCA activity than BT474 cells.

It is interesting to note that the two TNBC cell lines, like in other aspects of metabolism, also appear to be metabolically distinct with regard to nucleotide and nucleotide sugar metabolism. MDA-MB-231 cells had low ${ }^{13} \mathrm{C}$ enrichment from media $\left[\mathrm{U}-{ }^{13} \mathrm{C}\right]$-glucose in uridine and AXP while it was higher for the nucleotide sugars, while the opposite was mostly true for MDA-MB-468 cells. In our related study on treatment response differences, we used untargeted metabolomics and evaluated circulating inflammatory biomarker data to identify differences between these lines, based on the ethnic origin of the women the lines were established from. MDA-MB-468 cells were established from a sample taken from an African American woman, while MDA-MB-231 cells were established from a Caucasian woman [32-36]. Because TNBC has demonstrated health disparities, by ethnicity, in terms of incidence, mortality, and outcomes linked to responsiveness to treatment $[2,6,9-$ $15,37-41]$, it is reasonable that we continue to see differences between the lines at the level of energy utilization.

3.3. Amino Acid Metabolism. There was similarly high ${ }^{13} \mathrm{C}$ glycine production from media $\left[\mathrm{U}_{-}{ }^{13} \mathrm{C}\right]$-glucose in both BT474 and MDA-MB-468 cells and little to no detectible production in MCF-7 and MDA-MB-231 cells. Predictably, this trend was also seen in the ${ }^{13} \mathrm{C}$ enrichment of the glycine moiety of glutathione ( $\gamma$-glu-cys-gly). Unfortunately, due to peak overlap, we were not able to discern the glutamate moiety of glutathione from glutamine or free glutamate in the ${ }^{13} \mathrm{C}$ spectra. This de novo glutathione production in the BT474 and MDA-MB-468 cells may be indicative of their capacity to respond to oxidative stress and overcome hypoxic microenvironment conditions, processes which have been linked to decreased treatment responsivity, increased metastatic potential, and antiapoptotic function [42-44].

There were other differences in amino acid concentrations and production beyond what has been discussed. Of particular interest is the observation that the consumption of the branched chain amino acids (isoleucine, leucine, and valine) from the media occurs in a trend roughly opposite to that of glucose. For instance, MCF-7 cells have the highest glucose consumption but the lowest valine consumption, 


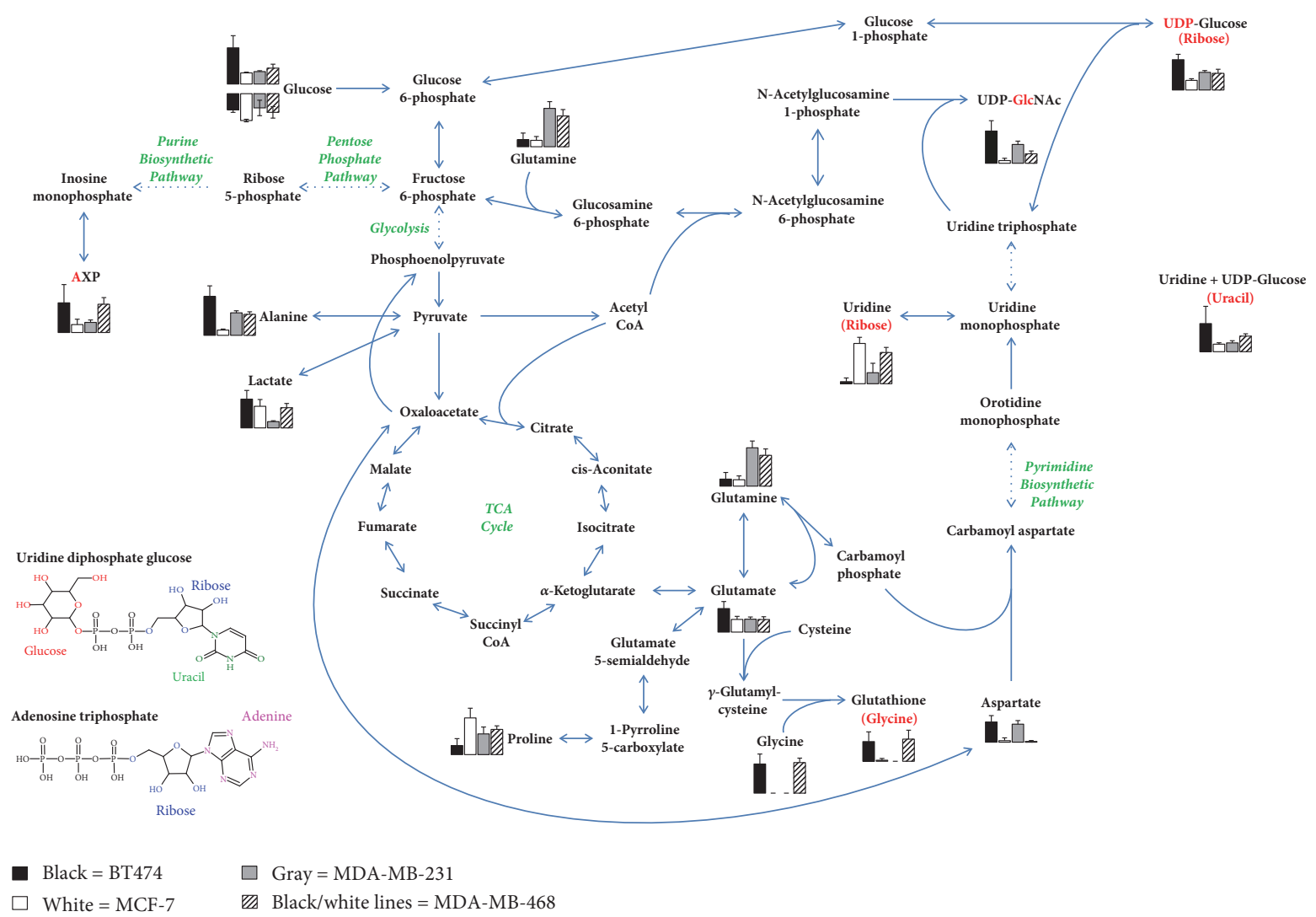

(a) Metabolic pathway showing intracellular ${ }^{13} \mathrm{C}$ concentrations of various metabolites from cells grown with ${ }^{13} \mathrm{C}$-glucose supplemented media. The negative bars for glucose indicate media consumption

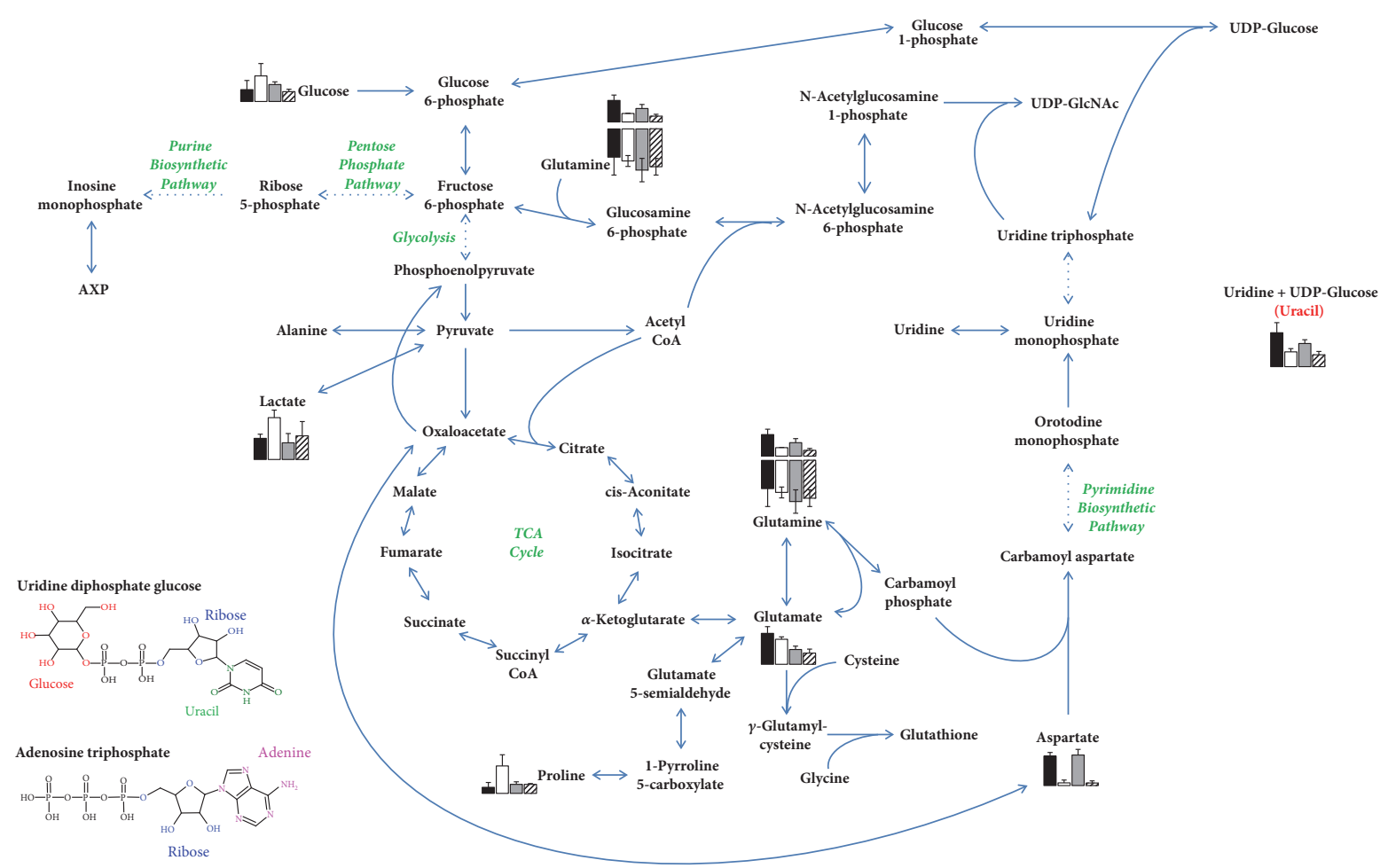

Black $=$ BT 474

$\square$ Gray $=$ MDA-MB- 231

$\square$ White $=$ MCF-7 Black $/$ white lines $=$ MDA-MB-468

(b) Metabolic pathway showing intracellular ${ }^{13} \mathrm{C}$ concentrations of various metabolites from cells grown with ${ }^{13} \mathrm{C}$-glutamine supplemented media. The negative bars for glutamine indicate media consumption 


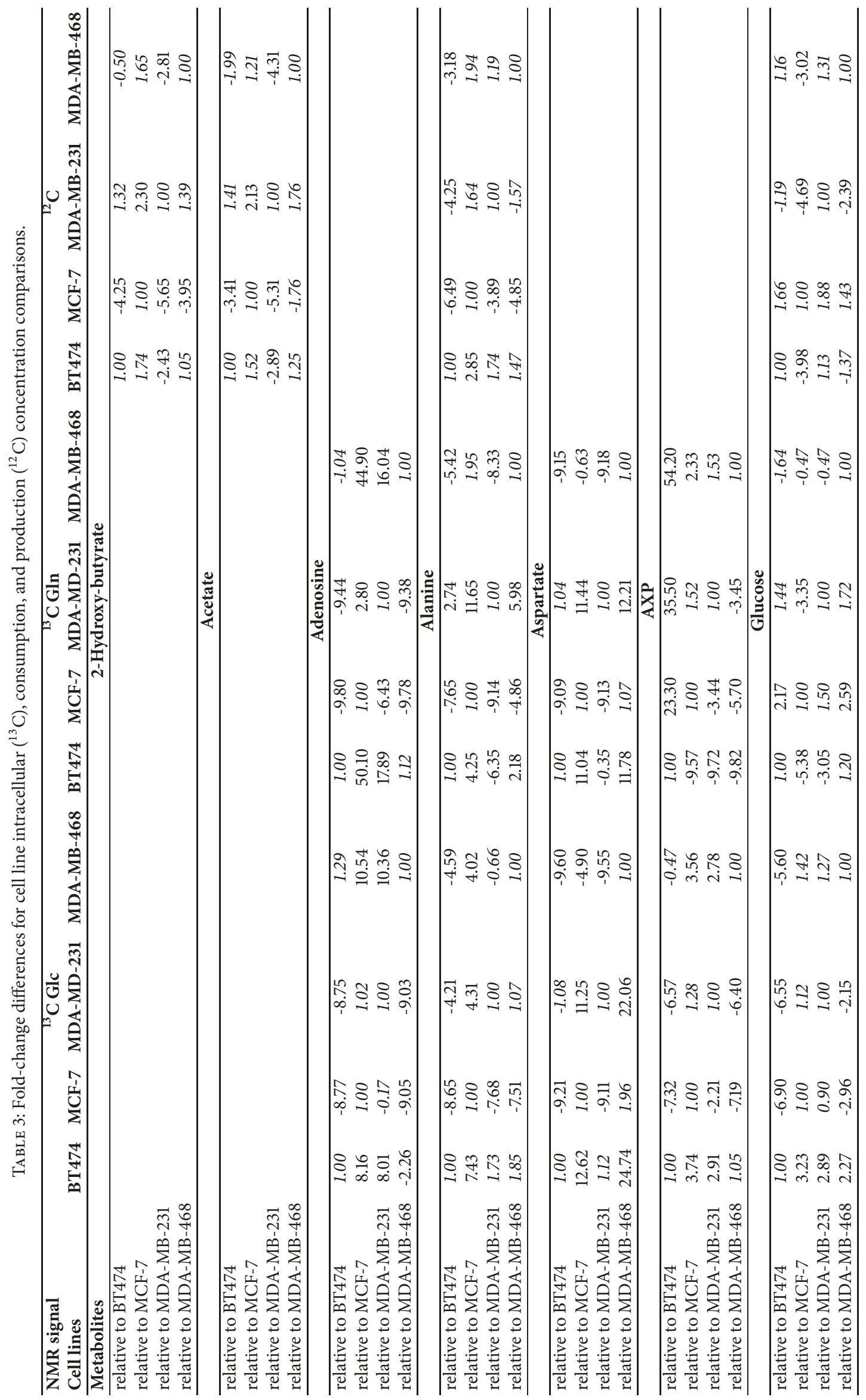




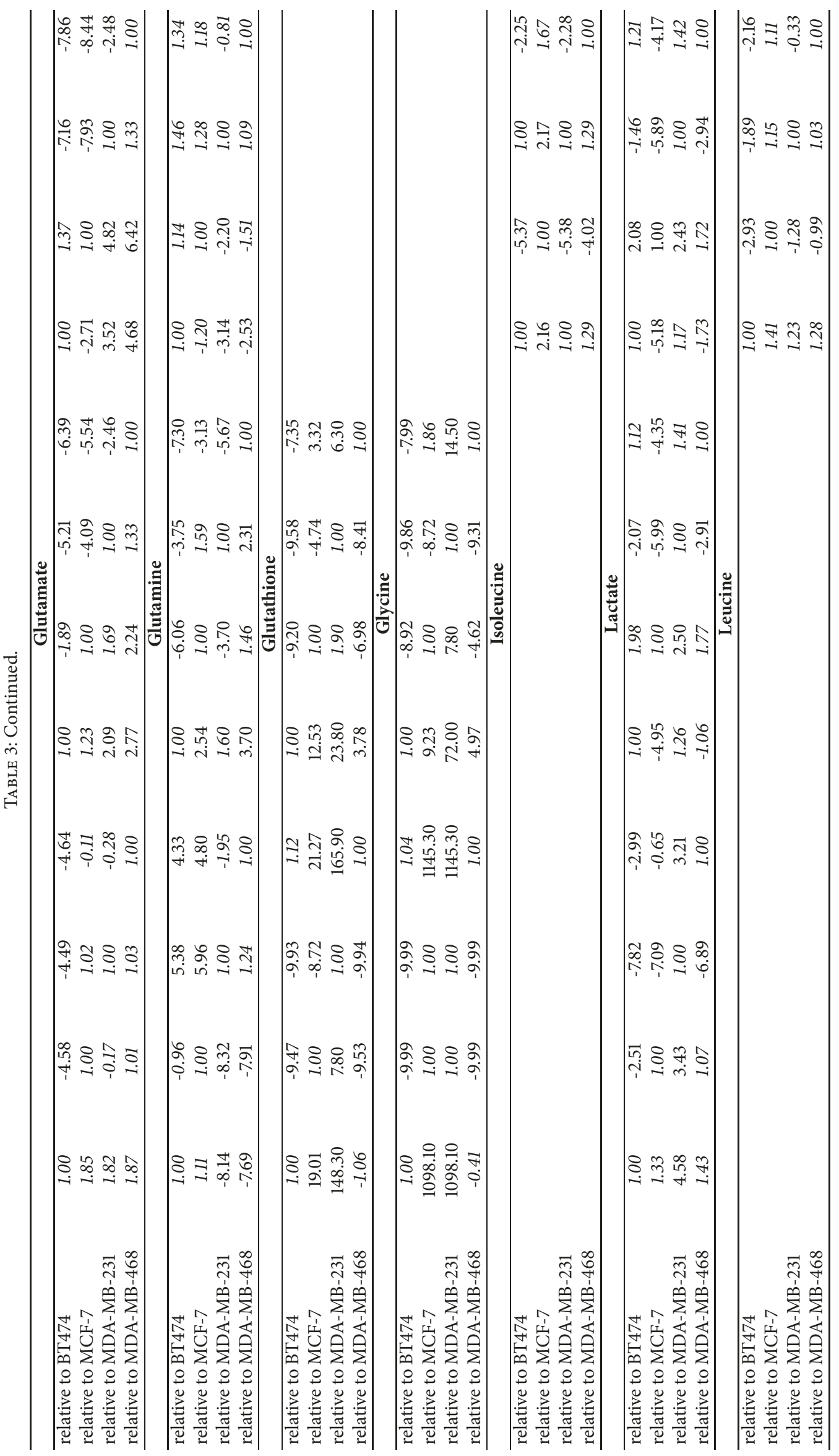




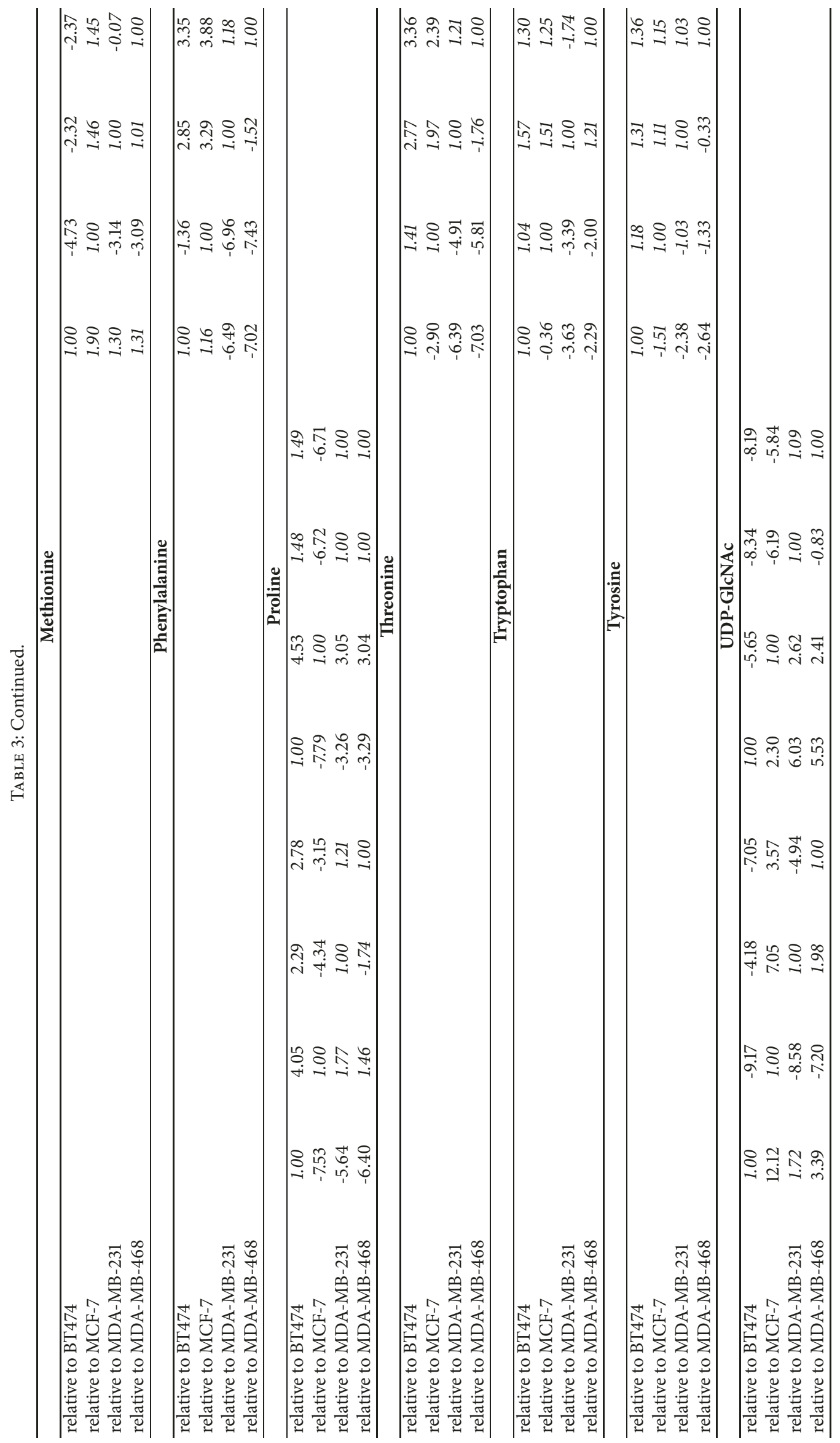




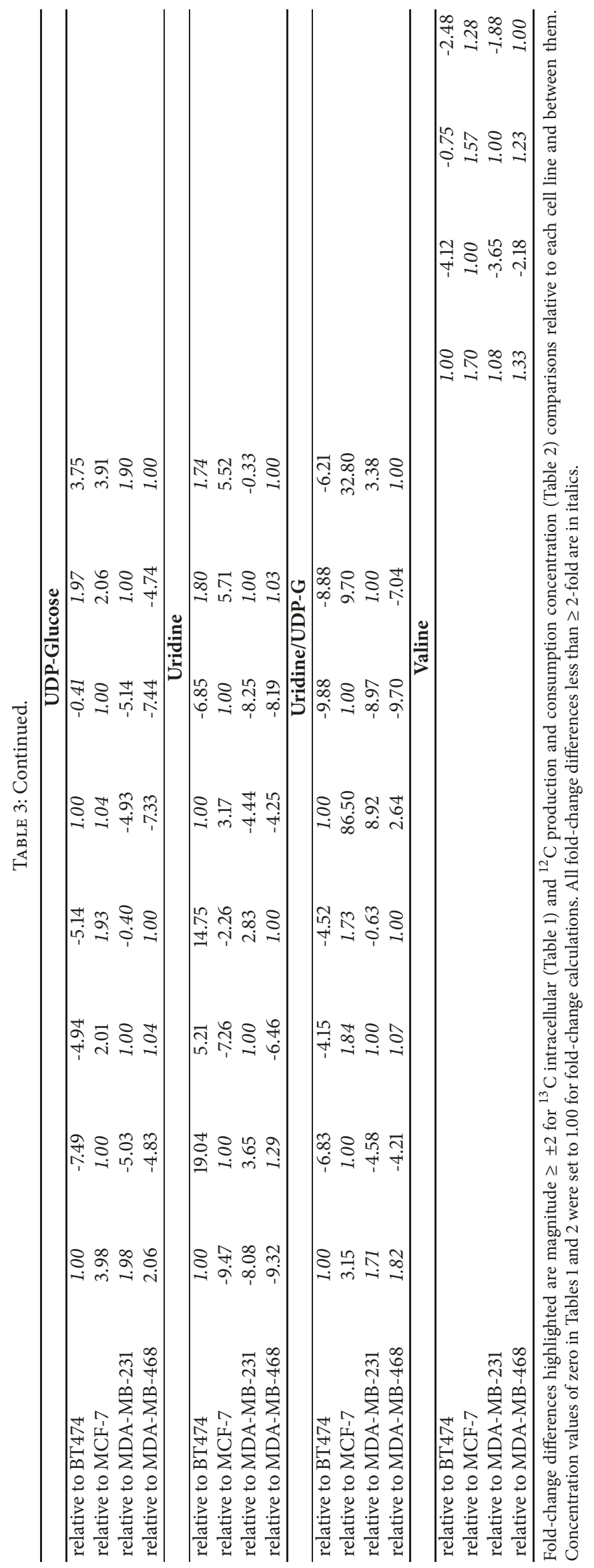


whereas BT474 and MDA-MB-231 cells have the lowest glucose consumption but the highest valine consumption. Consumption of other aromatic amino acids or methionine was unremarkable. Intracellular concentrations of both aromatic and branched chain amino acids follow roughly the same trend, where MDA-MB-231 and BT474 had the highest concentration, and the TNBC line had the highest concentration, but MCF-7 and MDA-MB-468 cells had lower concentrations by comparison. Overall, intracellular concentrations mirrored uptake from the media.

\section{Conclusions}

The addition of ${ }^{13} \mathrm{C}$ substrates to the media uncovered many findings that were not possible using "traditional" methodologies involving ${ }^{12} \mathrm{C}$ substrates. Since the majority of lactate production is from glucose and a much smaller amount is from glutamine, use of ${ }^{13} \mathrm{C}$-glutamine in the media allows the production of lactate from glutamine to be observed. Similarly, production of both glutamate and glutamine from glucose, as well as production of glucose from glutamine, can be observed using media containing ${ }^{13} \mathrm{C}$-glucose or ${ }^{13} \mathrm{C}$-glutamine, respectively. The ${ }^{13} \mathrm{C}$ measurements, which represent production from the ${ }^{13} \mathrm{C}$ substrate, differ from their ${ }^{12} \mathrm{C}$ counterparts, which represent total pools of the given metabolite. Additionally, de novo synthesis of many compounds that are recycled or partially degraded can be observed using ${ }^{13} \mathrm{C}$ substrates. ${ }^{13} \mathrm{C}$ measurements of AXP and GSH from media containing ${ }^{13} \mathrm{C}$-glucose are different from their ${ }^{12} \mathrm{C}$ counterparts. Thus, the ${ }^{13} \mathrm{C}$ measurements would be indicative of de novo synthesis rather than the total pools of these heavily recycled metabolites. Finally, using the ${ }^{13} \mathrm{C}$ experimental procedure, we were able to measure metabolites, notably proline and uridine (Figure 2), that would have been otherwise difficult for concentration fit, because they have ${ }^{1} \mathrm{H}$ NMR spectral peaks that are masked by other larger peaks.

Our data demonstrate the utility of stable isotoperesolved metabolomics to differentiate $\mathrm{BCa}$ cells lines, classified by the same clinical subtype based on hormone receptor status, by differences in energy utilization. These characteristic differences should be considered when designing effective targeted treatment strategies. To that end, future studies with sufficient power will statistically test the differences observed in metabolites that play a role in cellular energetics. Next, we could determine how differences in energy utilization in BCa cell line models correlate with basal energy utilization requirements using normal mammary cells, to identify metabolically driven mechanisms and potentially novel therapeutic targets.

\section{Conflicts of Interest}

Study support was solely from Grant 1U24DK097193-01, as detailed above. Otherwise, no conflicts of interest relevant to this article including financial interests, activities, relationships, and affiliations are disclosed for any of the authors.

\section{Authors' Contributions}

Jason H. Winnike and Delisha A. Stewart contributed equally to work and are co-first authors.

\section{Acknowledgments}

This research was supported by the NIH Common Fund award through the National Institute for Diabetes and Digestive and Kidney Diseases to the NIH Eastern Regional Comprehensive Metabolomics Resource Core at UNC-Chapel Hill, Nutrition Research Institute (1U24DK097193-01, PISumner).

\section{Supplementary Materials}

Supplementary file contains Supplemental Figure 1, demonstrating specified NMR spectral regions that are different across Luminal A and TNBC cell lines for (A) ${ }^{13} \mathrm{C}$-glucose or (B) ${ }^{13}$ C-glutamine metabolism. (Supplementary Materials)

\section{References}

[1] S. F. Brockmöller, E. Bucher, B. M. Müller et al., "Integration of metabolomics and expression of glycerol-3-phosphate acyltransferase (GPAM) in breast cancer-link to patient survival, hormone receptor status, and metabolic profiling," Journal of Proteome Research, vol. 11, no. 2, pp. 850-860, 2012.

[2] C. E. DeSantis, S. A. Fedewa, A. G. Sauer, J. L. Kramer, R. A. Smith, and A. Jemal, "Breast cancer statistics, 2015: convergence of incidence rates between black and white women," $C A$ : $A$ Cancer Journal for Clinicians, vol. 66, no. 1, pp. 31-42, 2016.

[3] S. Louie, E. Grossman, L. Crawford et al., "GSTP1 Is a Driver of Triple-Negative Breast Cancer Cell Metabolism and Pathogenicity," Cell Chemical Biology, vol. 23, no. 5, pp. 567-578, 2016.

[4] AC. Society, Cancer Facts Figures, American Cancer Society, Atlanta, 2016.

[5] D. A. Stewart, Y. Yang, L. Makowski, and M. A. Troester, "Basallike breast cancer cells induce phenotypic and genomic changes in macrophages," Molecular Cancer Research, vol. 10, no. 6, pp. 727-738, 2012.

[6] Foundation TNBC, Living Beyond Breast Cancer Guide To UnderstandingTriple-Negative Breast Cancer, 2012.

[7] Institute NIoH-NC, "Cancer Fact Sheets - Breast," in Surveillance, Epidemiology, and End Results Program, 2014.

[8] B. P. Schneider, E. P. Winer, W. D. Foulkes et al., "Triple-negative breast cancer: Risk factors to potential targets," Clinical Cancer Research, vol. 14, no. 24, pp. 8010-8018, 2008.

[9] K. C. Amirikia, P. Mills, J. Bush, and L. A. Newman, "Higher population-based incidence rates of triple-negative breast cancer among young African-American women. Implications for breast cancer screening recommendations," Cancer, vol. 117, no. 12, pp. 2747-2753, 2011.

[10] L. A. Carey, C. M. Perou, C. A. Livasy et al., "Race, breast cancer subtypes, and survival in the Carolina Breast Cancer Study," The Journal of the American Medical Association, vol. 295, no. 21, pp. 2492-2502, 2006.

[11] J. E. Cunningham, A. J. Montero, E. Garrett-Mayer, H. J. Berkel, and B. Ely, "Racial differences in the incidence of breast cancer 
subtypes defined by combined histologic grade and hormone receptor status," Cancer causes \& control : CCC, vol. 21, no. 3 , pp. 399-409, 2010.

[12] L. A. Field, B. Love, B. Deyarmin, J. A. Hooke, C. D. Shriver, and R. E. Ellsworth, "Identification of differentially expressed genes in breast tumors from African American compared with Caucasian women," Cancer, vol. 118, no. 5, pp. 1334-1344, 2012.

[13] B. E. Henderson, N. H. Lee, V. Seewaldt, and H. Shen, "The influence of race and ethnicity on the biology of cancer," Nature Reviews Cancer, vol. 12, no. 9, pp. 648-653, 2012.

[14] R. C. Millikan, B. Newman, C.-K. Tse et al., "Epidemiology of basal-like breast cancer," Breast Cancer Research and Treatment, vol. 109, no. 1, pp. 123-139, 2008.

[15] V. W. Setiawan, K. R. Monroe, L. R. Wilkens, L. N. Kolonel, M. C. Pike, and B. E. Henderson, "Breast Cancer Risk Factors Defined by Estrogen and Progesterone Receptor Status: The Multiethnic Cohort Study," American Journal of Epidemiology, vol. 169, no. 10, pp. 1251-1259, 2009.

[16] J. Yeh, J. Chun, S. Schwartz et al., "Clinical Characteristics in Patients with Triple Negative Breast Cancer," International Journal of Breast Cancer, vol. 2017, Article ID 1796145, 5 pages, 2017.

[17] W. D. Foulkes, I. E. Smith, and J. S. Reis-Filho, “Triple-negative breast cancer," The New England Journal of Medicine, vol. 363, no. 20, pp. 1938-1948, 2010.

[18] F. O. Ademuyiwa, M. J. Ellis, and C. X. Ma, "Neoadjuvant Therapy in Operable Breast Cancer: Application to Triple Negative Breast Cancer," Journal of Oncology, vol. 2013, Article ID 219869, 8 pages, 2013.

[19] S. Bayraktar and S. Glück, "Molecularly targeted therapies for metastatic triple-negative breast cancer," Breast Cancer Research and Treatment, vol. 138, no. 1, pp. 21-35, 2013.

[20] C. A. Hudis and L. Gianni, “Triple-Negative Breast Cancer: An Unmet Medical Need," The Oncologist, vol. 16, no. Supplement 1, pp. 1-11, 2011.

[21] D. Hanahan and R. A. Weinberg, "Hallmarks of cancer: the next generation," Cell, vol. 144, no. 5, pp. 646-674, 2011.

[22] D. Hanahan and R. A. Weinberg, "The hallmarks of cancer," Cell, vol. 100, no. 1, pp. 57-70, 2000.

[23] J. Budczies, B. M. Pfitzner, B. Györffy et al., "Glutamate enrichment as new diagnostic opportunity in breast cancer," International Journal of Cancer, vol. 136, no. 7, pp. 1619-1628, 2015.

[24] A. Le, A. N. Lane, M. Hamaker et al., "Glucose-independent glutamine metabolism via TCA cycling for proliferation and survival in b cells," Cell Metabolism, vol. 15, no. 1, pp. 110-121, 2012.

[25] D. R. Wise and C. B. Thompson, "Glutamine addiction: a new therapeutic target in cancer," Trends in Biochemical Sciences, vol. 35 , no. 8, pp. 427-433, 2010.

[26] D. A. Stewart, J. H. Winnike, S. L. McRitchie, R. F. Clark, W. W. Pathmasiri, and S. J. Sumner, "Metabolomics Analysis of Hormone-Responsive and Triple-Negative Breast Cancer Cell Responses to Paclitaxel Identify Key Metabolic Differences," Journal of Proteome Research, vol. 15, no. 9, pp. 3225-3240, 2016.

[27] T. TeSlaa and M. A. Teitell, "Techniques to Monitor Glycolysis," in Conceptual Background and Bioenergetic/Mitochondrial Aspects of Oncometabolism, vol. 542 of Methods in Enzymology, pp. 91-114, Elsevier, 2014.

[28] T. W. Fan, A. N. Lane, R. M. Higashi, and J. Yan, "Stable isotope resolved metabolomics of lung cancer in a SCID mouse model," Metabolomics, vol. 7, no. 2, pp. 257-269, 2011.
[29] P. Lorkiewicz, R. M. Higashi, A. N. Lane, and T. W. Fan, "High information throughput analysis of nucleotides and their isotopically enriched isotopologues by direct-infusion FTICRMS," Metabolomics, vol. 8, no. 5, pp. 930-939, 2012.

[30] O. Warburg, "The effect of hydrogen peroxide on cancer cells and on embryonic cells," Acta - Unio Internationalis Contra Cancrum, vol. 14, no. 1, pp. 55-57, 1958.

[31] J. T. Camp, F. Elloumi, E. Roman-Perez et al., "Interactions with fibroblasts are distinct in basal-like and luminal breast cancers," Molecular Cancer Research, vol. 9, no. 1, pp. 3-13, 2011.

[32] B. R. Brinkley, P. T. Beall, L. J. Wible, M. L. Mace, D. S. Turner, and R. M. Cailleau, "Variations in cell form and cytoskeleton in human breast carcinoma cells in vitro," Cancer research, vol. 40, no. 9, pp. 3118-3129, 1980

[33] R. Cailleau, M. Olive, and Q. V. J. Cruciger, "Long-term human breast carcinoma cell lines of metastatic origin: preliminary characterization," In Vitro Cellular \& Developmental Biology Animal, vol. 14, no. 11, pp. 911-915, 1978.

[34] R. Cailleau, R. Young, M. Olivé, and W. J. Reeves, "Breast tumor cell lines from pleural effusions," Journal of the National Cancer Institute, vol. 53, no. 3, pp. 661-674, 1974.

[35] S. Pathak, M. J. Siciliano, R. Cailleau, C. L. Wiseman, and T. C. Hsu, "A human breast adenocarcinoma with chromosome and isoenzyme markers similar to those of the HeLa line," Journal of the National Cancer Institute, vol. 62, no. 2, pp. 263-271, 1979.

[36] M. J. Siciliano, P. E. Barker, and R. Cailleau, "Mutually exclusive genetic signatures of human breast tumor cell lines with a common chromosomal marker," Cancer research, vol. 39, no. 3, pp. 919-922, 1979.

[37] "Race/Ethnicity Risk Factors Ardmore, PA 190032014," http://www.breastcancer.org/risk/factors/race_ethnicity.

[38] T. H. Keegan, M. C. DeRouen, D. J. Press, A. W. Kurian, and C. A. Clarke, "Occurrence of breast cancer subtypes in adolescent and young adult women," Breast Cancer Research, vol. 14, no. 2, 2012.

[39] T. H. Keegan, D. J. Press, L. Tao et al., "Impact of breast cancer subtypes on 3-year survival among adolescent and young adult women," Breast Cancer Research, vol. 15, no. 5, 2013.

[40] A. W. Kurian, K. Fish, S. J. Shema, and C. A. Clarke, "Lifetime risks of specific breast cancer subtypes among women in four racial/ethnic groups," Breast Cancer Research, vol. 12, no. 6, article R99, 2010.

[41] L. A. Sturtz, J. Melley, K. Mamula, C. D. Shriver, and R. E. Ellsworth, "Outcome disparities in African American women with triple negative breast cancer: a comparison of epidemiological and molecular factors between African American and Caucasian women with triple negative breast cancer," $B M C$ Cancer, vol. 14, no. 1, article 62, 2014.

[42] N. S. Brown and R. Bicknell, "Hypoxia and oxidative stress in breast cancer Oxidative stress - its effects on the growth, metastatic potential and response to therapy of breast cancer," Breast Cancer Research, vol. 3, no. 5, 2001.

[43] M. Fiocchetti, M. Cipolletti, S. Leone et al., "Neuroglobin in Breast Cancer Cells: Effect of Hypoxia and Oxidative Stress on Protein Level, Localization, and Anti-Apoptotic Function," PLoS ONE, vol. 11, no. 5, p. e0154959, 2016.

[44] H. J. Knowles and A. L. Harris, "Hypoxia and oxidative stress in breast cancer Hypoxia and tumourigenesis," Breast Cancer Research, vol. 3, no. 5, 2001. 


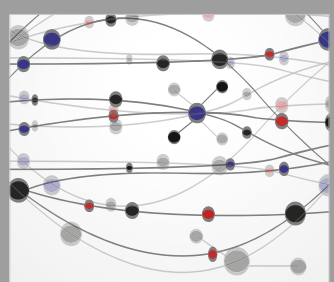

The Scientific World Journal
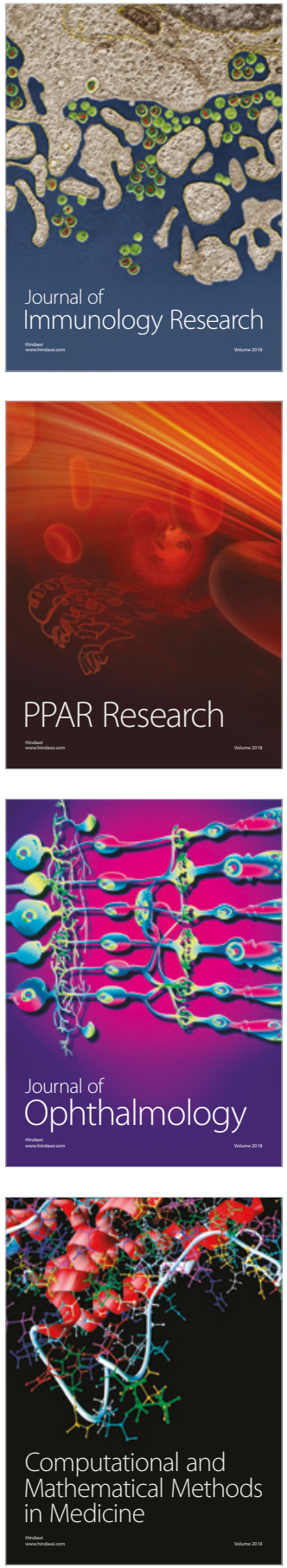

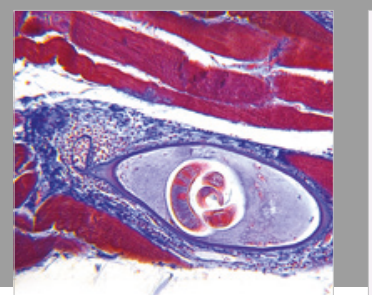

Gastroenterology Research and Practice

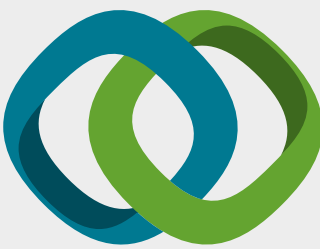

\section{Hindawi}

Submit your manuscripts at

www.hindawi.com
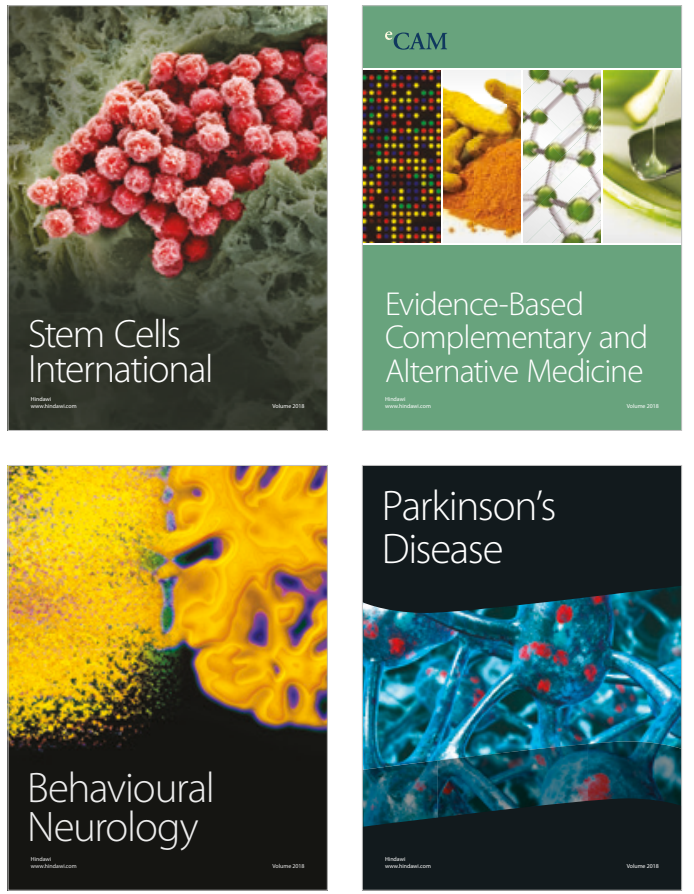

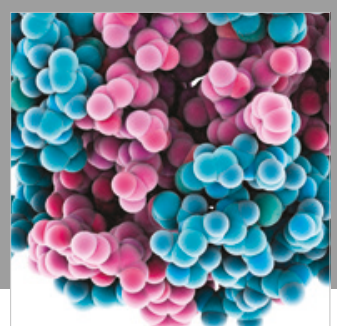

ournal of

Diabetes Research

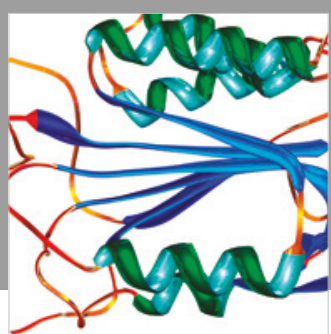

Disease Markers
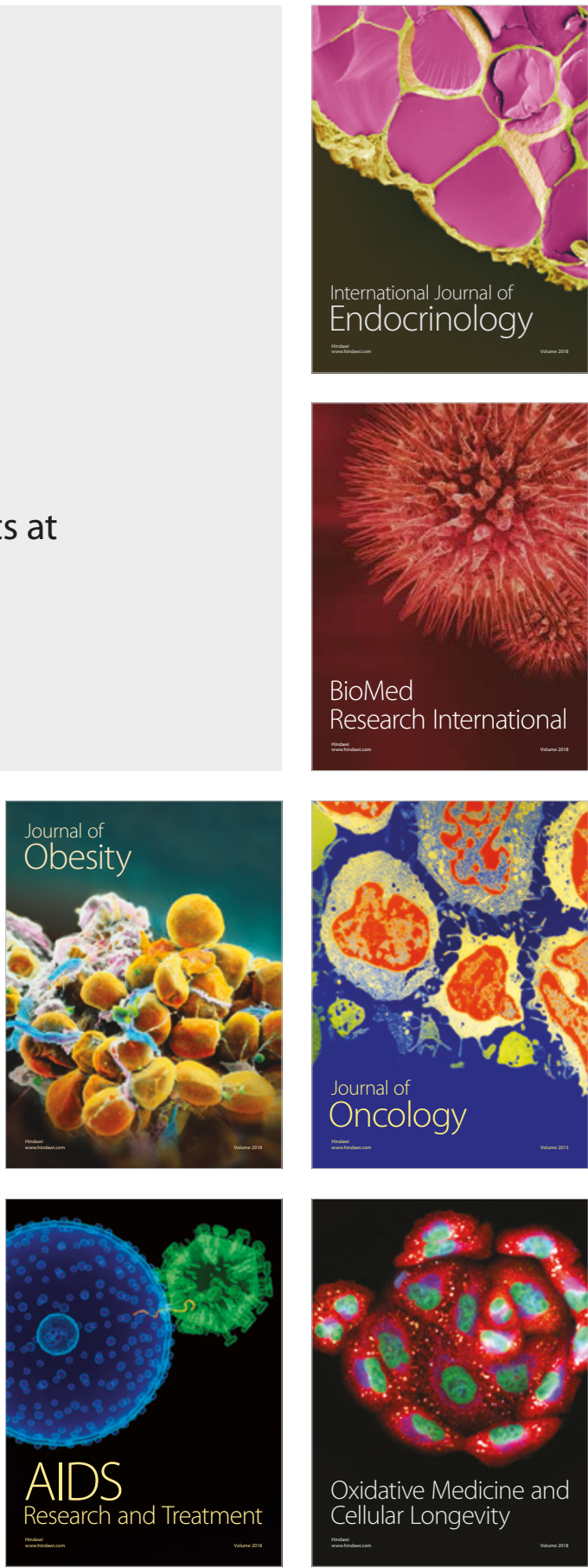